\title{
Status of sexual and reproductive health and rights in Zambia: Contraception and family planning, preventing unsafe abortion and accessing post abortion care, and maternal health
}

Population Council

Follow this and additional works at: https://knowledgecommons.popcouncil.org/departments_sbsr-rh

Part of the Demography, Population, and Ecology Commons, Family, Life Course, and Society Commons, International Public Health Commons, and the Women's Health Commons How does access to this work benefit you? Let us know!

\section{Recommended Citation}

"Status of sexual and reproductive health and rights in Zambia: Contraception and family planning, preventing unsafe abortion and accessing post abortion care, and maternal health," Policy brief. Lusaka: Population Council, 2017. 


\section{STATUS OF SEXUAL AND REPRODUCTIVE HEALTH AND RIGHTS IN ZAMBIA}

Contraception and Family Planning, Preventing Unsafe Abortion and Accessing Postabortion Care, and Maternal Health

This brief is Part 1 of a three-part series entitled "Status of Sexual and Reproductive Health and Rights in Zambia," reporting on progress, gaps, and existing challenges in SRH\&R.

In 1994, the International Conference on Population and Development (ICPD) affirmed that Sexual and Reproductive Health and Rights (SRH\&R) are human rights. Pursuant to this, several international instruments contributed to global consensus on how reproductive health rights are intrinsically linked to other

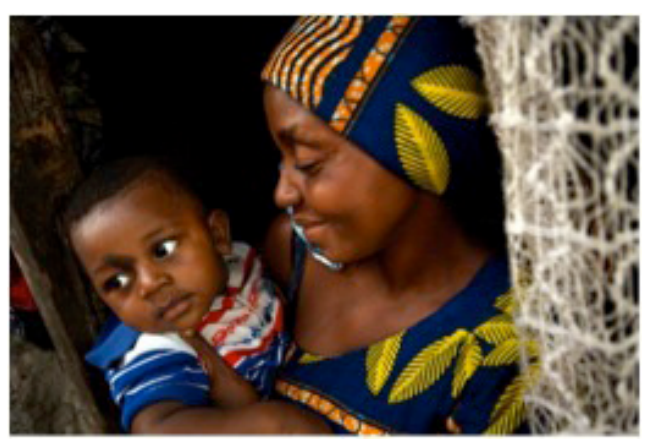
fundamental human rights. The Government of the Republic of Zambia (GRZ) has fully committed to fulfilling the SRH\&R of all people by ratifying 11 international instruments of law (seven global and four regional treaties; see Table 1).

In addition to ratifying global and regional treaties, Zambia has also committed to achieving Sustainable Development Goals (SDGs). Some SDGs directly relate to SRH\&R. These are: ensuring healthy lives and promoting well-being for all at all ages (Goal 3); ensuring quality education for all (4); achieving gender equality and empowering all women and girls (5); reduced inequalities (10), and enhancing partnerships to achieve SDGs (17). Other SDGs have an indirect effect on SRH\&R. These include decent work (8), and peace, justice, and strong institutions (16). Government is therefore obligated to ensure that it respects, protects, and fulfils every person's rights.

Using a human-rights-based approach, the Government of Zambia under the leadership of the Human Rights Commission, and in collaboration with the United Nations Population Fund, Office of the High Commissioner for Human Rights, Women and Law in Southern Africa, with technical facilitation by the Population Council, conducted an assessment of the status of SRH\&R in the country guided by a global assessment framework (see Table 2). The aim was to assess Zambia's commitment to fulfilling government obligations on seven SRH\&R-related themes. The themes, selected through a consensus-building approach, are: (1) access to contraceptive information and services; (2) access to safe abortion and postabortion-care services; (3) maternal health care; (4) prevention and treatment of HIV; (5) comprehensive sexuality 
education; (6) violence against women and girls; and (7) rights of marginalised populations, particularly adolescents and sex workers. The working questions were:

a) Do national SRH indicators show that Zambia is meeting the sexual and reproductive rights of all of its people?

b) Are the country's existing laws, policies, financing mechanisms, budgetary allocations, implementation measures, monitoring and evaluation, and remedial and redress mechanisms respecting, protecting, and upholding SRH\&R in Zambia?

\section{KEY FINDINGS}

Overall, under each theme, based on the assessment framework and informed by desk reviews and consultative processes, Zambia is making steady progress in fulfilling $\mathrm{SRH} \& \mathrm{R}$, although challenges still remain.

\section{Access to Contraceptive Information and Services, Including Family Planning \\ Human Rights Considerations and Government Obligations}

The convention on the Elimination of All Forms of Discrimination Against Women (CEDAW) (Article 16(1)[e]) and the Protocol to the African Charter on Human and People's Rights on the Rights of Women in Africa (Article 1[b]) guarantee the right of all women and couples to determine the number and spacing of children and provide for the right to access information and education on family planning (FP). The government is therefore obliged to provide comprehensive information on contraception and FP, and to guarantee a wide range of contraceptive choices.

\section{Legal and Policy Environment}

To ensure the right to contraceptive information and services, the government launched a Reproductive Health Policy in 2005 that guarantees free contraceptives in public health facilities. In 2006, the Zambia Family Planning National Guidelines and protocols were published to offer guidance for health-care workers on how to provide quality FP services, and in 2014 the government published the Zambia Integrated Family Planning Scale Up Plan for 2013-20. Working with civil society partners and the media, the government has been disseminating information on contraceptives and FP. All of these efforts have led to improvements in contraceptive use and FP services in Zambia.
Indicators of Progress

Knowledge of contraceptives is universal, with 99\% of women having knowledge about at least one modern contraceptive method, and $23 \%$ of married women and $27 \%$ of unmarried but sexually active women of reproductive age having knowledge about emergency contraception. As a result, between 2002 and 2014, modern contraceptive use has increased from 34\% to $45 \%$ and unmet need for contraception has declined from a high of $27 \%$ to $21 \%$ (see Figure 1) (CSO, MOH, and ICF International 2014). However among married adolescents (15-19), unmet need is significantly high (25.1\%) which indicates that adolescent girls would like to access contraceptives but are unable to.

\section{Gaps and Challenges}

There are significant inequalities in contraceptive use in Zambia. While urban and educated women seem to have easy access to contraceptives, rural and uneducated women face challenges (see Figure 2). In rural areas, challenges such as long distances to health facilities, traditional barriers such as male spouses prohibiting women from using contraceptives, and desire to have children hinder women from making a choice to use FP services.

Although unmet need is declining, it is high in rural areas at $24.1 \%$ as compared to $16.7 \%$ in urban areas, and at $25.1 \%$ among adolescents (CSO, MOH, and ICF International 2014).

The contraceptive method mix is limited, especially in rural areas. The most commonly used contraceptives are injectables used by $19 \%$ of married women, followed by pills (12\%). The use of long-acting and reversible contraceptives (LARCs), such as implants and intrauterine devices (IUDs), is significantly low in Zambia. This limits women's ability to freely choose the type of contraceptives that meet their needs.

High teenage pregnancy in Zambia indicates that adolescent-friendly and responsive FP services are lacking for adolescents. The lack of access to contraceptive and FP services affects their well-being. Teenage pregnancy often leads to school dropout, which affects a girl's future and may lead to child marriage and health complications related to teenage pregnancy, such as fistula and unsafe abortion. 
Figure 1: Progress on contraceptive indicators

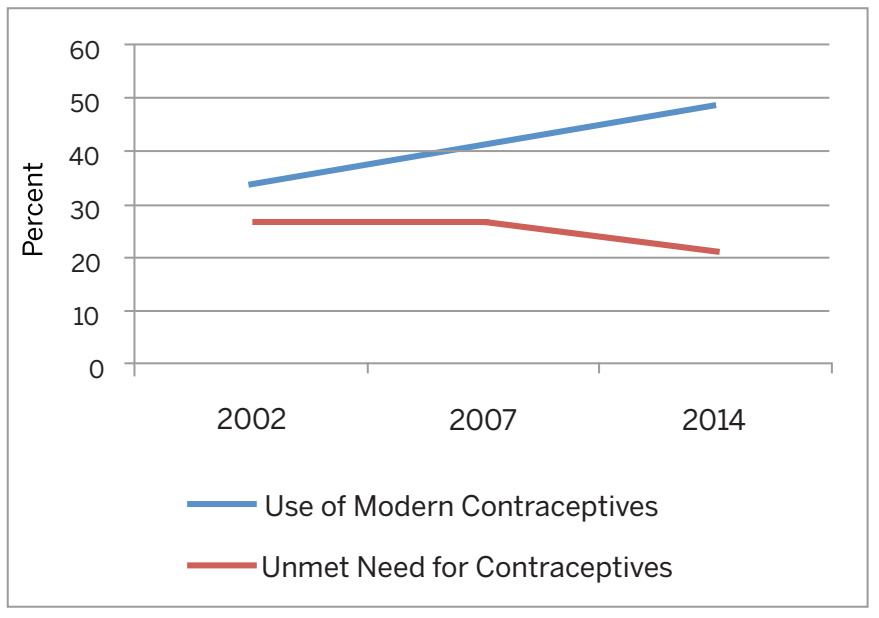

While Zambia collects information on fertility rates, there are no data on subfertility and infertility, and therefore there is a lack of information on how people with infertility problems can have their SRH\&R met.

\section{Access to Safe Abortion and Postabortion Care}

Human Rights Considerations and Government Obligations

Unsafe abortion may lead to injury, disability, or death among women and girls. In fact, in 2014-15 abortion complications accounted for $13.3 \%$ of maternal deaths in Zambia. The Government of the Republic of Zambia (GRZ) has ratified the Protocol to the African Charter on Human and People's Rights on the Rights of Women in Africa, which directs government to “... protect the reproductive rights of women by authorising medical abortion in cases of sexual assault, rape, incest, and where the continued pregnancy endangers the mental and physical health of the mother or the life of the mother or the foetus." GRZ has therefore an obligation to protect women and girls from unsafe abortion.

\section{Legal and Policy Environment}

Abortion is legal in Zambia. There are two principal laws that concern abortion-the Penal Code Chapter 87 of the laws of Zambia and the Termination of Pregnancy Act of 1972. The Penal code prohibits unsafe abortion. In sections 151 and 152, the Penal Code prohibits abortion by a pregnant woman herself or assisted by any other person to procure an abortion. A person found guilty of an illegal abortion is liable to imprisonment for a term of 14 years. However, safe abortions are legally provided for under the Termination of Pregnancy Act of 1972, which allows
Figure 2: Contraceptive use by geography and women's education level

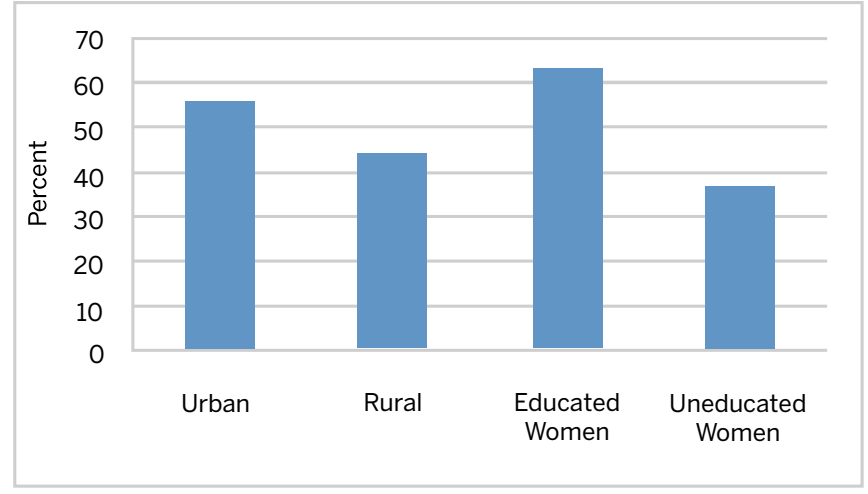

abortion. The Penal Code in Section 152(2) (2005 amendment) allows abortion for girls below 16 years of age who were raped. In 2009, Zambia developed comprehensive standards and guidelines on safe abortion; marriage; and sexual cleansing.

\section{Gaps and Challenges}

In spite of positive legal and policy environment, the number of unsafe abortions is high. In 2014-15, 33.3\% of health facilities provided postabortion care (PAC), yet only $5 \%$ actually performed termination of pregnancy (ToP). The highest number of pregnancy terminations in health facilities was in urban areas: In Lusaka province, $19.7 \%$ of health facilities provided ToP, followed by Central Province at $12.8 \%$ and Copperbelt at $11.2 \%$. The rural provinces of Luapula and Eastern province recorded none, while Western Province recorded $0.7 \%$. Although rural provinces recorded no safe pregnancy terminations in health facilities, or had the lowest rates of safe abortion performed in health facilities, they had the highest PAC services by health facilities for women and girls who suffered abortion complications. In rural Luapula, for instance, $57.8 \%$ of health facilities provided PAC, with $62.2 \%$ and $42 \%$ in Muchinga and Western provinces, respectively, suggesting that the majority of abortions both in urban and rural areas are unsafe, resulting in complications requiring medical attention (Ministry of Health 2015).

Women and girls, especially those in rural areas, are not enjoying their right to safe abortion in Zambia. This is mainly because the conditions to terminate pregnancy are too difficult to fulfil (see Termination of Pregnancy box). Christianity is the predominant religion in Zambia, there is much stigma against abortion, and society in general frowns upon women and girls who abort. 
Conditions under which Termination of

Pregnancy is Allowed-Section 3(1) of

Termination of Pregnancy Act:

- A pregnancy should be terminated by a registered medical practitioner assisted by two other registered medical practitioners, one of whom should be a specialist in the branch of medicine in which the patient is specifically required to be examined.

- When the continuance of the pregnancy would involve risk to the life of the pregnant woman, or risk of injury to the physical or mental health of the pregnant woman, or risk of injury to the physical or mental health of any existing children of the pregnant woman, greater than if the pregnancy were terminated.

- When there is substantial risk that if the child were born he or she would suffer from such physical or mental abnormalities as to be seriously handicapped.

\section{Recommendations}

- Raise awareness among women and clinicians, including an information campaign, that abortion legislation allows women to seek safe abortions at health centres.

- $\quad$ Provide women and girls access to good quality services for the management of complications arising from unsafe abortions.

- $\quad$ Strengthen and expand efforts to increase knowledge and access to affordable contraceptive methods and emergency contraception throughout the country and ensure that women and girls, especially in rural areas, do not face barriers accessing family planning information and services.

- Amend the Termination of Pregnancy Act to ensure that termination of pregnancy and postabortion care are easily accessible, including abortion services in health institutions other than hospitals, and allow other trained health personnel who are not doctors to approve abortion.

- Amend the Penal Code to allow abortion for women older than 16 who have been raped, to terminate a pregnancy resulting from rape.

\section{Maternal Health Care}

Human Rights Considerations and Government Obligations

Women have the right to life and to the highest attainable standard of health, equality, and nondiscrimination. The Convention on the Elimination of All forms of Discrimination Against Women (CEDAW) in Article 12, the International Covenant on Economic, Social, and Cultural Rights (ICESCR) in Article 12, and the Protocol to the African Charter on Human and People's Rights on the Rights of Women in Africa in Article 14 place an obligation on government to ensure that women attain a high standard of health and to reduce maternal and child deaths. GRZ has an obligation to ensure that women and teenage girls have access to high-quality and efficient maternal health care services that reduce maternal mortality.

\section{Legal and Policy Environment}

Government is progressively creating a conducive legal and policy environment to ensure that women and teenage girls do not die in childbirth. The Constitution guarantees the right to life. Although Zambia has not yet ratified the optional protocol to the ICESCR on the abolition of the death penalty, a pregnant woman cannot be sentenced to death. In the Employment Act in Section 15A(1), Zambia has provided for maternity leave for all working women, and in section 54(2) has provided one day of rest to every working woman for which they do not need to produce a medical certificate. This day is popularly known as Mother's Day. The Employment Act and all other laws do not, however, provide for paternity leave.

To prevent maternal death, several policies have been put in place. The national health policy, the national reproductive health policy, the national health strategic plan, and the roadmap for accelerating reduction of maternal, newborn, and child mortality 2013-16 all focus on reducing maternal mortality. To achieve these policies, several programmes have been implemented: the roadmap to reduce maternal mortality, the Campaign for Accelerated Reduction of Maternal Mortality (CARMMA), the Maternal Death Surveillance and Response (MDSR), Emergency Obstetrics and Newborn Care (EmONC), and the Creation of Community-based volunteer groups, including Safe Motherhood Action Groups (SMAGS).

Indicators of Progress

Zambia is making slow progress in meeting its obligations. The maternal mortality ratio (MMR) has significantly 
declined from a high of 729 deaths per 100,000 live births in 2001 to 398 deaths per 100,000 live births in 2014 (see Figure 3). The number of women delivering in health facilities has been increasing, from 43\% in 2001 to $47 \%$ in 2007 and to $64 \%$ in 2014 (see Figure 4.)

\section{Gaps and Challenges}

Progress is too slow. At 398 deaths per 100,000 live births, Zambia's maternal mortality ratio (MMR) is among the highest in the world when compared to Namibia whose MMR is 200 per 100,000 live births, or Botswana's 160 per 100,000, and significantly higher when compared to developed countries such as Norway, with only 7 deaths per 100,000 live births.

The major contributing factors to maternal deaths are:

Distance to health facilities: A lot of women and girls die at home or on the way to health facilities, particularly in rural areas where the average distance to the nearest health facility is $15 \mathrm{~km}$ as compared with $5 \mathrm{~km}$ in urban areas. While transport may be readily available in urban areas, that is not the case in rural areas.

Delays in receiving medical care in health facilities: In health facilities, women die as a result of excessive bleeding, sepsis, obstructed labour, and eclampsia, all of which are preventable. However, shortages of health care workers, particularly midwives, obstetricians and gynaecologists, poor infrastructure, and lack of Emergency Obstetrics and Newborn Care (EmONC) services directly affect the ability of women and teenage girls to access quality health care. Based on the WHO recommendations, Zambia is supposed to have 150 health facilities competent in providing EmONC services, yet in 2015 only 68 were available, which is $45 \%$ of the recommended minimum (Ministry of Health 2015).

Gender inequalities: Zambia is a patriarchal society in which women have low status. Men influence decisions on when to access maternal services and they control financial resources that can facilitate quick access to services when needed.

\section{Recommendations}

- Strengthen the health-care systems-build more health facilities to reduce distances in accessing them; train and recruit adequate medical personnel; improve road infrastructure, particularly in rural areas, to ease transport challenges to health facilities.
- Implement Maternal Death Surveillance and Response (MDSR) in all maternal health service delivery points

- Ensure that maternal health services, including EmONC, are available, accessible, and of high quality in all rural communities in order to fulfil the SRH\&R of all rural women and girls.

- Ensure maternal death surveillance and response in all health facilities in Zambia.

- Establish national maternal and safe-motherhood sensitisation programs for rural communities and women who have limited education, and ensure that programs are in local languages. Take advantage of community radio stations to disseminate safemotherhood programs in local languages in rural areas.

\section{Accountability Framework}

As part of accountability on SRH\&R, Zambia's state party to the international conventions is obligated to report to the international community on its compliance with international human rights law. However, Zambia reports very late to relevant treaty bodies. For example, Zambia ratified the CEDAW on 21 June 1985; the first report to the CEDAW committee at the United Nations was due 21 July 1986 but was submitted on 6 March 1991. Since then Zambia has submitted two other reports, the most recent submitted on 5 January 2010 after two reminders from the CEDAW committee. Similarly, Zambia ratified the Convention on the Rights of the Child (CRC) on 6 December 1991, and its first report to the CRC committee was due on 4 January 1994. The report was submitted in November 2001, and the second report which was due on 4 June 2009 was submitted in August 2013. To ensure accountability, it is important that Zambia reports in a timely manner to relevant treaty bodies.

To accelerate the fulfilment of SRH\&R of all people in Zambia, there is a need for government to increase the budgets for services and ensure that there is an accountability framework that holds government accountable to its commitments. Although the national budget for health reached $11.3 \%$ of the total national budget in 2013, it has dropped to $9.9 \%$ and $9.6 \%$ in the 2014 and 2015 budgets, respectively. These figures fall short of the Abuja Declaration in which African governments, including Zambia, committed to allocating at least $15 \%$ of their national budget to health. Zambia should work toward achieving that goal so that more resources are allocated to health and to SRH in particular. 
Figure 3: Maternal mortality ratio

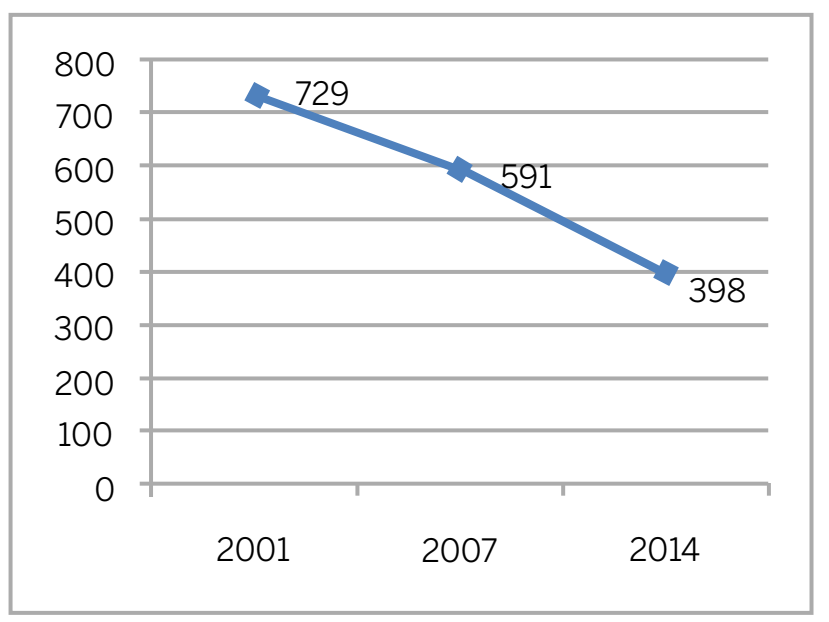

The accountability framework does exist in the form of parliamentary committees, the High Court, the Human Rights Commission, and civil society organisations. However, it is fragmented and not well coordinated, which leaves the national accountability framework for SRH\&R weak. There is a need to strengthen the accountability framework in order to ensure that duty bearers are held accountable to their commitments to SRH\&R in Zambia.

\section{Conclusion}

In general, progress has been made in meeting government obligations to respect, protect, and fulfil the SRH\&R of all people in Zambia. In most thematic areas assessed, statistics show improvements. For example, maternal deaths and HIV prevalence have significantly reduced; knowledge and use of FP services has improved, and postabortion-care services are available. Comprehensive Sexuality Education has been introduced in schools and progress is being made to ensure CSE reaches out-ofschool adolescents. National policies have been developed, and progressive laws have been enacted. There are bills (Marriage Bill and Child Code Bill) pending enactment into law that will contribute to improvements in meeting people's SRH\&R needs in Zambia. In spite of these achievements, progress is very uneven across geographic locations and segments of population. Women and girls in rural areas are disadvantaged-especially those who have limited education. Progress is too slow among rural populations and uneducated women and girls with regard to such issues as use of modern contraceptive methods and access to information on $\mathrm{SRH}$, including FP, maternal health, and gender stereotyping. While urban areas enjoy relatively easy access to health and to justice, this is not the case in rural areas where distances to health facilities
Figure 4: Deliveries in health facilities

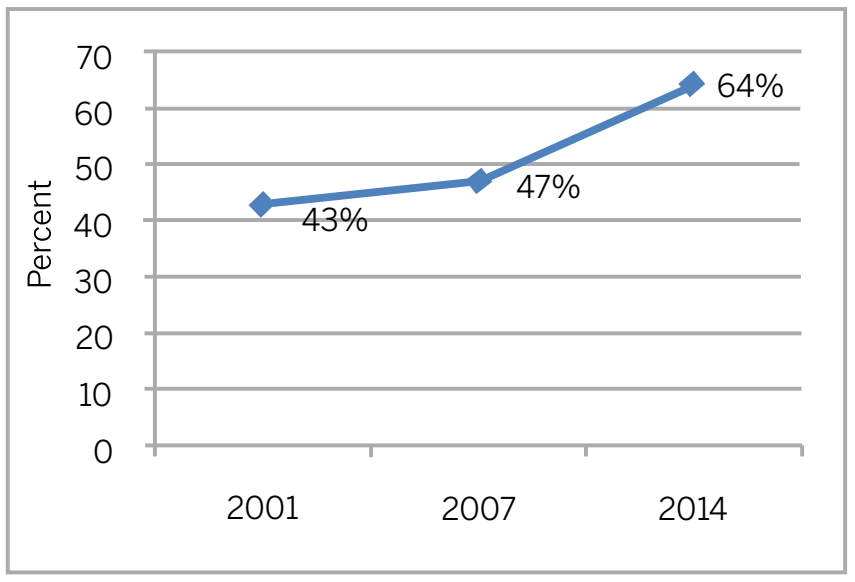

and judicial services hinder people, particularly women and girls, from seeking services and redress in cases of abuse and rights violations.

Zambia must do much more to guarantee the rights of vulnerable populations. This brief has established that data are limited regarding the numbers and needs of all vulnerable population groups present in the country. Data collection, and research into the SRH\&R of these vulnerable groups, will be an essential step toward improving SRH\&R. The involvement of vulnerable groups through participation and enhanced accountability can also play a role in improving SRH\&R. Adolescents are subsets of vulnerable population groups that need attention. High teenage pregnancy, HIV prevalence, and child marriage are all issues that require immediate attention to ensure that adolescents' SRH\&R needs are met.

Examining barriers through the human-rights-based approach helps identify actions that need to be taken to improve SRH\&R in Zambia. There is therefore a need to strengthen the accountability framework that will utilise human-rights-based approaches and hold GRZ accountable for fulfilling its human-rights obligations. This framework would monitor and ensure that the government is complying with international and national commitments while also using various national institutions, and government and nongovernment actors, to ensure implementation of the recommendations identified in the assessment, and ultimately achieve progressive attainment of SRH\&R for all individuals in Zambia. 
Table 1: Global and regional treaties ratified by Zambia

\begin{tabular}{|c|c|c|}
\hline \multicolumn{3}{|c|}{ Global treaties } \\
\hline & Treaty & $\begin{array}{l}\text { Date of } \\
\text { ratification }\end{array}$ \\
\hline 1. & $\begin{array}{l}\text { International Convention on the } \\
\text { Elimination of All forms of Racial } \\
\text { Discrimination }\end{array}$ & 4 Feb 1972 \\
\hline 2. & $\begin{array}{l}\text { International Covenant on Economic, Social, } \\
\text { and Cultural Rights }\end{array}$ & 10 Apr 1984 \\
\hline 3. & $\begin{array}{l}\text { International Covenant on Civil and } \\
\text { Political Rights }\end{array}$ & 10 Apr 1984 \\
\hline 4. & $\begin{array}{l}\text { Convention on the Elimination of All Forms } \\
\text { of Discrimination Against Women }\end{array}$ & 21 Jun 1985 \\
\hline 5. & Convention on the Rights of the Child & 6 Dec 1991 \\
\hline 6. & $\begin{array}{l}\text { Convention Against Torture and Other } \\
\text { Cruel, Inhuman or Degrading Treatment or } \\
\text { Punishment }\end{array}$ & 7 Oct 1998 \\
\hline 7. & $\begin{array}{l}\text { Convention on the Rights of } \\
\text { Persons with Disabilities }\end{array}$ & 1 Feb 2010 \\
\hline \multicolumn{3}{|c|}{ African regional treaties } \\
\hline 8. & $\begin{array}{l}\text { African Charter on Human and } \\
\text { People's Rights }\end{array}$ & 1 Oct 1984 \\
\hline 9. & $\begin{array}{l}\text { Protocol to the African Charter on } \\
\text { Human and People's Rights on the Rights } \\
\text { of Women in Africa }\end{array}$ & 2 May 2006 \\
\hline 10. & African Youth Charter & 16 Sep 2009 \\
\hline 11. & $\begin{array}{l}\text { SADC Protocol on Gender and } \\
\text { Development }\end{array}$ & 26 Nov 2012 \\
\hline
\end{tabular}

Table 2: Assessment Framework

\begin{tabular}{|c|c|c|c|}
\hline Themes assessed & Indicators of progress & $\begin{array}{l}\text { Local laws guaranteeing } \\
\text { SRH\&R }\end{array}$ & $\begin{array}{l}\text { Gaps and challenges in } \\
\text { progressive realisation of } \\
\text { rights }\end{array}$ \\
\hline $\begin{array}{l}\text { Access to contraceptive } \\
\text { information and services } \\
\text { Access to safe abortion } \\
\text { and postabortion-care } \\
\text { services } \\
\text { Maternal health care } \\
\text { Prevention and treatment } \\
\text { of HIV } \\
\text { Comprehensive sexuality } \\
\text { education } \\
\text { Violence against women } \\
\text { and girls } \\
\text { Rights of vulnerable } \\
\text { populations }\end{array}$ & $\begin{array}{l}\text { On each of these themes: } \\
\text { Are indicators showing } \\
\text { improvements toward } \\
\text { upholding the rights of all } \\
\text { people in Zambia? }\end{array}$ & $\begin{array}{l}\text { On each of these themes: } \\
\text { Are there laws and } \\
\text { policies respecting and } \\
\text { protecting the SRH\&R of } \\
\text { all people? } \\
\text { Are these laws and } \\
\text { policies being fully } \\
\text { enforced and } \\
\text { implemented? }\end{array}$ & $\begin{array}{l}\text { On each of these themes: } \\
\text { What are the legal and } \\
\text { human rights gaps and } \\
\text { challenges that should be } \\
\text { addressed? }\end{array}$ \\
\hline
\end{tabular}




\section{References}

Central Statistical Office (CSO), Ministry of Health (MOH), and ICF International, 2014. Zambia Demographic and Health Survey (ZDHS) 2013-14. Rockville, Maryland, USA.

Ministry of Health (MOH). 2015. Zambia National Emergency Obstetric and Newborn Care (EmONC) Needs Assessment 2014-15. Preliminary Report 2015.

Suggested citation: Population Council, UNFPA,

Government of Zambia Human Rights Commission, WLSA, and United Nations in Zambia. 2017. “The Status of Sexual and Reproductive Health and Rights in Zambia: Contraception and Family Planning, Preventing Unsafe Abortion and Accessing Postabortion Care, and Maternal Health Care." Lusaka, Zambia.

Photo credits: United Nations Population Fund; Population Council

The Human Rights Commission protects, promotes and advocates for Human Rights. It undertakes research, legislative reviews, human rights education as well as investigations of human rights abuses and violations in Zambia. hrc.org.zm

The Population Council conducts research and delivers solutions that improve lives around the world. Big ideas supported by evidence: It's our model for global change. popcouncil.org.

\section{United Nations Population Fund (UNFPA)}

Delivering a world where every pregnancy is wanted, every childbirth is safe and every young person's potential is fulfilled. unfpa.org

\section{United Nations in Zambia}

Delivering as One.

Women and Law in Southern Africa (WLSA) responds to the socio-legal needs of women and develops mechanisms to guarantee women's rights. wlsazambia.org 